\title{
Layered Double Hydroxides Nanomaterials in Biomedicine and (bio) Sensing Design
}

\author{
Elena Florentina Grosu*1,2, Dana Simiuc ${ }^{3}$ and Renato Froidevaux ${ }^{1}$ \\ ${ }^{1}$ Department of Chemical Engineering, Institut Charles Viollette, F-59000 Lille, France \\ ${ }^{2}$ Department of Chemical Engineering, Technical University Gh. Asachi, Romania \\ ${ }^{3}$ Laboratoire de Physique des Lasers, UMR 8523 Université Lille 1-CNRS, France
}

Received: January 31, 2018; Published: February 22, 2018

*Corresponding author: Elena Florentina Grosu, department of Chemical engineering, Artois, University Littoral Côte d'Opale, EA 7394, ICV - Institut Charles Viollette, F-59000 Lille, France, Email: elena_grosu89@yahoo.com

\begin{abstract}
Novel devices and materials are designed by exploring the nano scale properties of the matter. Nano and biomaterials can be combined together and further used as efficient tools in engineering, biomedicine, electronics and biotechnology. Layered double hydroxide, also called anionic clays, are a class of hydrotalcite nanocomposites with a large potential of utilization in nano and biotechnology. They have a high compositional diversity, are able of self-assembly and in presence of biomolecules they behave like soft materials, with no significant effect on their structure or activity. Some of the fields were the LDHs nanomaterials were successfully used are drug and gens delivery, cosmetics, cancer therapy and biosensing.
\end{abstract}

Keywords: Anionic clays; Drug delivery; Enzyme immobilization; Nanomaterials

Abbrevations: LDHs: Layered Double Hydroxides; DCF: Di-Clo-Fenac; BBC: Ber-Berine Chloride; CA: Cinnamic Acid; HRP: Horseradish Peroxidase; GCE: Glass Carbon Electrode; HBV: Hepatitis B virus

\section{Introduction}

Nature is the most powerful and ingenious build maker. Piece by piece and step by step, nature created the largest source of inspiration and gave it to us with free and full access. Understanding how nature works at nanoscale level, humans started to imitate it and in this way different products and technologies were obtained and developed. Nanomaterials and nanotechnology are relatively new directions in research, being intensively approached by scientists in physics, chemistry, medicine, biology and engineering. Some of them are focused in improvement and development of new process and technologies, which can be used to obtain new materials with enhanced properties. In this context, nano-size materials are promising in fields such as environmental protection, electronics, medicine, electrical engineering, catalysis, biotechnology, energy, information technology, etc [1]. The most important aspect regarding the nano form of the matter is that at scales ranging from individual atoms or molecules to submicron dimensions, the properties of matter change, and are very different from those of the same material, but in a bulk form. For example, some chemical elements like gold or silver are non-toxic in bulk form, but as nanoparticles are capable of killing viruses upon contact [2]. In the last years, a class of inorganic materials, usually called anionic clays, has paid the attention of researchers from different fields. Layered double hydroxides (LDHs) are a nanocomposite class, whose organization is based on the structure of brucite $(\mathrm{Mg}(\mathrm{OH}) 2)$ in which a part of divalent cations have been replaced by trivalent cations [3]. These materials are investigated due to their special properties and have technological importance in catalysis, drug delivery, medical science, cosmetics, biosensing, nanocomposite material engineering [4]. This paper presents an overview on the most recently application of LDHs in biomedicine and biosensing.

\section{Structural Characteristics of Layered Double Hydroxides}

Layered double hydroxides are known for over 150 years. The first discovered natural mineral with this structure was hydrotalcite [5], reported by Hochstetter in 1842, synthesized 100 years later by Feitknecht [6]. The structure of this compound is related to that of brucite in which part of $\mathrm{Mg}^{2+}$ cations are replaced by $\mathrm{Al} 3+$. Carbonate anions are intercalated between the layers to maintain the electroneutrality of material. The presence of hydrotalcite in nature is reduced. For this reason, the synthesis of LDHs was 
investigated and was concluded that many transition metals in the first series can be used to obtain new materials with layered structure [7]. Layered double hydroxides present a basic character and a great ability to intercalate anions in their structure [8]. They have many of the physical and chemical properties of the mineral clay, being capable of ion exchange [7]. The LDHs can be obtained by substitution of divalent cations in brucite with trivalent cations, so that the layers have a positive charge, which is balanced by intercalation of anions between layers. Also it is possible to vary the type and the ratio of di- and trivalent cations, as well as the type of anion in the interlayer space [5]. Possibilities for obtaining LDHs structures with controllable properties, is one of the most attractive features of these compounds [9].

The general formula of LDHs materials is:

Where

a) $\mathrm{MII}=$ divalent cation $(\mathrm{Mg} 2+, \mathrm{Ca} 2+, \mathrm{Zn} 2+$, etc. $)$;

b) $\mathrm{MIII}=$ trivalent cation $(\mathrm{Al} 3+, \mathrm{Cr} 3+, \mathrm{Fe} 3+, \mathrm{Co} 3+$, etc. $)$;

c) $\mathrm{An}-=$ interlayer anion with charge n- (Cl-, CO32-, NO3-, etc.);

d) $\mathrm{x}$ represents the molar ratio of [M (III) /(M (II) + M (III))];

e) $y=$ number of water molecules located in the interlayer space $[8,9]$.

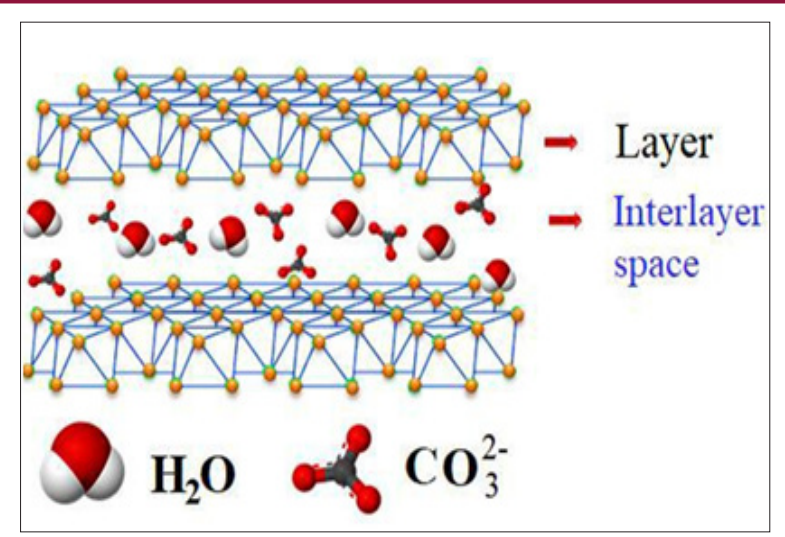

Figure 1: Schematic representation of hydrotalcite structure.

Although the general formula involves only the presence of di- and trivalent cations, were obtained materials having a similar structure, but containing monovalent ions of lithium [10,11-15], In addition, was shown that it is possible to incorporate tetravalent ions in LDH structures. Thus, have been synthesized in (Figure 1) is presented the hydrotalcite structure. The interlayer space of the material is occupied by anions, water molecules and sometimes other neutral or charged moieties [16].The linkage of these species is carried out by a complex network of hydrogen bonding. The connection between the layers and interlayer space involves a combination of electrostatic effect and hydrogen bonding. Because of layered structure of LDHs, the anions must satisfy excess positive charge on both of the octahedral layers, which are electrically balanced by two neighboring interlayers. The interactions between the layers and interlayer galleries are realized particularly by strongly polarized hydroxyl groups which are bonded to trivalent cations and interact with the interlayer anions [5].

\section{Layered Double Hydroxides in Biomedicine}

Biocompatibility: Recently, Cunha and co-worker elaborated a research on LDHs biocompatibility by testing two of the most popular LDHs materials, $\mathrm{ZnAl}-\mathrm{Cl}$ and $\mathrm{MgAl}-\mathrm{Cl}$. In their protocol, rats were implanted with sterile LDHs materials, the clay particles being introduced in the specimen muscles. 28 days after implantation, the results show low toxicity and a very good biocompatibility of LDHs, with tissue reconstruction and no inflammation [17]. In another study, rabbits were implanted with LDH. In the middle ear of the specimens were introduced MgAlLDH and the health animals evolution was monitored during 10 days. The material was highly biocompatible and slowly dissolved, being a promising nanocomposite for drug delivery [18].

Drug Delivery: One particular property of LDHs nanocomposite is their ability to incorporate large molecule as drugs. Furthermore, they can increase the drug solubility without the alteration of pharmaceutical therapeutic activity [19]. In a recent study, Dejbbi and collaborators prepared via co-precipitation and ionicexchange a drug-LDH hybrid between berberine chloride (BBC) and MgAlLDH. For both materials, denoted as BMAE (obtained via ionic exchange) and BMAC (obtained via co-cipitation), the drug was not incorporated in the LDH interlayer space, being adsorbed on clay surface. The release of BBC from biohybrids was carried out in PBS buffer, pH $7.4,37^{\circ} \mathrm{C}$. After 50 minutes, the equilibrium for the drug release is reached. Even if the reaction continued till 200 minutes, the maximum BBC release was $63 \%$ and $87 \%$ for BMAE and BMAC, respectively. In order to evaluate how the LDH matrix is affecting the therapeutic activity of $\mathrm{BBC}$, in vitro tests were performed. Different pathogen bacteria were put in contact with the BBC-LDHs biohybrids, for $24 \mathrm{~h}$. The results show that the bionanocomposites have anti-bacterial activity, and they can inhibit the pathogen proliferation [20].

Diclofenac (DCF) is an anti-inflammatory drug which was intercalated in the interlayer space of ZnAlLDH, through an ionexchange method. The DCF release had its maximum of $84 \%$ after cca. 600 minutes of stirring, at pH 7.4; the tests were carried out in phosphate buffer solutions with $\mathrm{pH} 7.4$ and $4.8,37^{\circ} \mathrm{C}$ [21]. Recently, efavirnez (EFZ), a pharmaceutical used as inhibitor for Human Immunodeficiency Virus, has successfully adsorbed on CaAlLDH. The EFZ drug is characterized by a poor solubility in water. However, when released from the LDHs surface, the drug solubility increases with $558 \%$ compared to the EFZ alone, after two hours. The cytotoxicity tests proved that CaAlLDH has a small effect on cells viability [22]. Vitamin $\mathrm{C}$ was also incorporated in CaAlLDH and released in phosphate buffer, pH 7.4 [23]. Other drugs which were coupled with layered double hydroxides are given in Table 1, together with some observation related on the way how the complex is formed (drug adsorption or interlayer intercalation) and the type of study [24-34]. 
Table 1: LDHs used in biomedical application.

\begin{tabular}{|c|c|c|c|}
\hline LDHs & Drug & Observation & Reference \\
\hline \multirow{3}{*}{ ZnTiLDH } & Ibuprofen, & Intercalated, release study & 24 \\
\hline & 2-mercaptobenzothiazole & $\begin{array}{l}\text { Intercalated, anti-microbial activity } \\
\text { study }\end{array}$ & 25 \\
\hline & Isonicotinic acid hydrazine & $\begin{array}{l}\text { Intercalated; anti-tuberculosis } \\
\text { therapy Increase of drug activity, } \\
\text { high Biocompatibility of LDH }\end{array}$ & 26 \\
\hline \multirow[b]{2}{*}{ ZnAlLDH } & Norfloxacin & Intercalated drug release study & 27 \\
\hline & doxorubicin & $\begin{array}{l}\text { Adsorption, anticancer therapy, } \\
\text { Superior biocompatibility of LDH }\end{array}$ & 28 \\
\hline \multirow{6}{*}{ MgAlLDH } & Pirenoxine sodium & $\begin{array}{l}\text { Intercalated; in vitro and in vivo } \\
\text { drug Release, ocular drug delivery. }\end{array}$ & 29 \\
\hline & Amoxicillin & $\begin{array}{l}\text { Incorporation, textural properties } \\
\text { study }\end{array}$ & 30 \\
\hline & 5-fluorouracil & Intercalated, Anticancer therapy. & 31 \\
\hline & Methotrexate & $\begin{array}{l}\text { Intercalated, in vivo studies on mice, } \\
\text { LDH non-toxic effect, antitumoral } \\
\text { therapy for osteosarcoma }\end{array}$ & 32 \\
\hline & Pifithrin- $\alpha-1$ & $\begin{array}{c}\text { Intercalated, in vivo release } \\
\text { study, good osteoinductivity and } \\
\text { cytocompatibility; }\end{array}$ & 33 \\
\hline & Raloxifene hydrochloride & $\begin{array}{l}\text { Intercalated, in vivo drug release } \\
\text { study, anticancer therapy, and high } \\
\text { biocompatibility. }\end{array}$ & 34 \\
\hline
\end{tabular}

Other LDHs Application in Biomedicine: Cârjă research group [35] obtained self-assembled gold nanoparticles (AuNPs) on LDHs matrix. The resulted hybrids were tested against hepatitis $B$ virus (HBV). Firstly, three type of LDH matrix were synthesized: MgAlLDH, ZnAlLDH and MgFeLDH. Furthermore, AuNPs/LDHs hybrids were obtained by exploring the structural memory effect of the anionic clays. For all the AuNPs/LDHs nanocomposite cytotoxicity and the antiviral activity were monitored. Results have shown that the hybrids have an inhibitory effect on HBV proliferation and a good cytocompatibility.Negatively charged organic molecules as DNA has been adsorbed on LDH by electrostatic binding [36] In a previews study done by Balcomb et al. in 2015 has been proved that the proprieties of LDHs nanocomposite (MgAlLDH, ZnAlLDH, $\mathrm{MgFeLDH}$ and $\mathrm{ZnFeLDH}$ ) recommend them as DNA delivery vector for mammalian cells transfection. In vitro tests carried out on hepatocellular carcinoma, embryonic kidney, and cervical cancer cell lines show low cytotoxic activity of LDH materials [37].

Another direction of LDH materials application is their utilization in cosmetics, especially for sunscreen formulation production [38]. The main issue of the existent sunscreen products is their organic content, which besides the UV absorption properties, they penetrate the skin and undesirable effects can occur. To avoid this, the organic compounds might be adsorbed on an inorganic matrix [39]. Some of the LDHs materials are excellent in UV radiation absorption [3941]. For this reason, the incorporation of organic molecules on clays structure can lead to a synergic effect in UV absorption. Recently, Li et al. intercalated in ZnTiLDH matrix the cinnamic acid (CA) and they evaluated the UV absorption properties. The results have proven that after intercalation, the resulted material (ZnTi-CA-
LDH) presents enhanced capacity of UV absorption. Furthermore, the hybrid was used for a cosmetic cream fabrication and the UV absorption capacity was measured and compared with a blank sample, without any ZnTi-CA-LDH in its composition.

The UV-Vis measurements have shown that the addition of the new material in the sun cream increases significantly the UV absorption ability of the final product [40]. Significant increase of UV radiation absorbance was observed for the hybrid resulted from the intercalation of benzophenone (B9) into ZnAlLDH matrix. Furthermore, in vitro studies were performed and the results have shown that the ZnAlLDH-B9 material had no significant cytotoxic effect on the human dermal fibroblasts cells [41].

Layered Double Hydroxide in (bio) Sensing: Layered double hydroxides are nanomaterials with high stability, low toxicity, variable morphological properties and significant adsorption capacity. Due to these characteristics, LDHs were perfect candidates for the immobilization of different molecules and biomolecules as DNA, drugs and enzymes [42]. Furthermore, they can be considerate as promising materials for electrochemical sensors and biosensor design.

Enzyme-LDHs as Biohybrid in Biosensors Design: The enzymes are biomolecules with catalytic activity which can be used in different processes due to their high specificity and efficiency [43]. LDHs nanocomposites have proven to be suitable supports for enzyme immobilization, without notable modification of enzyme activity [42]. One of the most important directions of enzyme immobilization on LDHs nanocomposites is their utilization in biosensing. Recently, tyrosinase enzyme was supported on CoAlLDH 
in order to obtain a biosensor able to detect the polyphenols, especially from tea. A robust polyphenols biosensor was designed by covering gold electrodes with $\mathrm{LDH}$, followed by tyrosinase binding to the modified electrodes. The biosensor was used many times with good performances, and it is appropriate to be used in fields where traces need to be detected (medicine, environment) [42]. Horseradish peroxidase (HRP) is an oxidoreductase used in biosensig for $\mathrm{H} 2 \mathrm{O} 2$ detection. In 2015 Wang designed a $\mathrm{H} 2 \mathrm{O} 2$ biosensor by attaching to a glass carbon electrode (GCE) a biohybride containing HRP immobilized on a mixture of carbon nanodots (C-Dots) and CoFeLDH.

The new biosensor reached its maximum performance at $\mathrm{pH} 7$ and it had superior analytical performances in terms of selectivity and detection limit in comparison with C-Dots/GCE, CoFeLDH/GCE, C-Dots/CoFeLDH/GCE formulation [44]. HRP was also immobilized on MgAlLDH [45], NiAlLDH [46]. Furthermore, horseradish peroxidase and glucose oxidase (GOX) were immobilized together on ZnCrLDH-ABTS composite. The bienzymatic biosensor was used for glucose determination. The operation principle involved the formation of $\mathrm{H} 2 \mathrm{O} 2$ as a product of glucose oxidation (reaction catalyzed by GOx), followed by HRP oxidation in presence of hydrogen peroxide, and HRP reduction by ABTS [47]. Other formulations for biosensors design were obtained from MgAlLDH [48,49], ZnAlLDH [49] and alkaline phosphatase for hydroquinone determination, MgAlLDH and acetylcholinesterase for organophosphate pesticides detection [50]. Also, for biosensing purpose, cellulase was immobilized on MgAlLDH [51]. Hemoglobin (Hb), which is an ironcontaining protein, was immobilized on exfoliated CoAlLDH [52] and ZnAlLDH [53]. Both Hb-LDH biosensors were used successfully for trichloroacetic acid biosensing, with high sensitivity and low detection limit.

LDHs in Non-Enzymatic Sensors Design: Beside the incorporation of active biomolecules into their structure, LDHs nanocomposites can be used alone or in combination with non-enzymatic materials for sensors fabrication. Particularly, hydrotalcites containing transition metals (e.g. $\mathrm{Mn}, \mathrm{Ni}, \mathrm{Co}$ ) are considerate as promising materials in electrochemistry [54]. Last year, Zhan et al. designed a sensor for bisphenol A (BPA) quantification [55]. For this, exfoliated NiAlLDH was deposited on glass carbon electrode (GCE) and used in BPA determination from milk. Sensor reproducibility, stability and selectivity were investigated. The results have shown that the product is highly selective, stable, having an excellent repeatability [55]. NiAlLDH was also the subject for acetylcholine (ACh) sensor design. Enhanced sensor electroconductivity was obtained when NiAlLDH material was combined with carbon dots [56].

Diabetes is a disease with a constantly increase of patients number. Efforts are focused on developing instruments and methods for rapid and accurate detection of glucose levels in human blood [57]. Glucose oxidase free sensors were intensely approached in the last years, because of the inconvenience like enzyme low stability and deactivation due to $\mathrm{pH}$ and temperature variation [58]. LDHs materials were used in non-enzymatic glucose detection. However, because of their low conductivity, the addition of carbon containing materials can solve this issue. Recently, Samuei et al. fabricated a graphene quantum dots - CoNiAlLDH sensor successfully used for glucose measurements from human blood sample [57]. Previously, NiCoLDH-carbon cloth [58] and Au-NiAlLDH-carbon nanotubesgraphen [59] sensor were designed for the same purpose. Furthermore, NiAlLDH attached on a carbon ionic liquid electrode was used for dopamine oxidation and quantification [60].

\section{Conclusion}

In this paper, layered double hydroxides applications in biomedicine and (bio) sensing were presented. Due to their proprieties as high physico-chemical stability, low toxicity and good compatibility with the living cells, the LDHs materials have been found as good candidates for drug delivery, sunscreen products fabrication and active biomolecules incorporation. In vivo and in vitro studies were done and the results have shown that the anionic clays have low cytotoxic effect, being able to increase the therapeutic activity and the solubility of some drugs. Furthermore, LDHs gold containing presented an inhibitory effect for hepatitis $B$ virus. Combined with enzyme or other non-enzymatic materials, the anionic clays were used for the fabrication of electrochemical sensors. It might be concluded that the layered double hydroxides are a class of biomaterials with a large potential in drug delivery, cancer therapy and bioimaging technology.

\section{References}

1. The Royal Society \& the Royal Academy of Engineering (2014) Nanoscience and nanotechnologies: opportunities and uncertainties, Nanoscience and nanotechnologies.

2. Logothetidis S (2012) Principles and Applications in Nanostructured Materials and Their Applications. Nanotechnology.

3. Hadnadjev Kostic M, Vulic T, Marinkovic Neducin R (2014) Solar light induced rhodamine B degradation assisted by TiO2-Zn-Al LDH based photocatalysts. Adv Powder Technolo 25(05): 1624-1633.

4. Saifullah B, Hussein MZ (2015) Inorganic nanolayers: structure, preparation, and biomedical applications. Int J Nanomedicine 10: 56095633.

5. Mingos DMP (2006) Structure and Bonding in Layered Double Hydroxides. Springer-Verlag Berlin Heidelberg, Germany.

6. Bravo-Suarez JJ, Paez-Mozo EA, Oyama ST (2004) Review of the synthesis of layered double hydroxides: a thermodynamic approach. Quim Nova 27: 601-614.

7. Forano C, Hibino T, Leroux F, Taviot-Gueho C (2006) Layered double hydroxides in Handbook of Clay Science, Developments in Clay Science pp. 1021-1094.

8. Basu D, Das A, Stöckelhuber KW, Wagenknecht U, Heinrich G (2014) Advances in layered double hydroxide (LDH)-based elastomer composites. Prog Polym Sci 39: 594-626.

9. Tonelli D, Scavetta E, Giorgetti M (2013) Layered-double-hydroxidemodified electrodes: electroanalytical applications. Anal Bioanal Chem 405: 603-614.

10. Chisem IC, Jones W (1994) Ion-exchange properties of lithium aluminium layered double hydroxides. J Mater Chem 4: 1737-1744.

11. Gupta S, Agarwal DD, Banerjee S (2012) Lithium Aluminium Layered Double Hydroxides: Synthesis and Application in Poly (Vinyl Chloride). Int J Polym Mater Po 61: 985-998. 
12. Tichit D, Das N, Coq B, Durand R (2012) Preparation of Zr-Containing Layered Double Hydroxides and Characterization of the Acido-Basic Properties of Their Mixed Oxides. Chem Mater 14: 1530-1538.

13. Chaparadza A, Hossenlopp JM (2011) Removal of 2,4-dichlorophenoxyacetic acid by calcined $\mathrm{Zn}$-Al-Zr layered double hydroxide. J Colloid Interface Sci 363: 92-97.

14. Velu S, Suzuki K, Osaki T, Ohashi F, Tomura S (1999) Synthesis of new Sn incorporated layered double hydroxides and their evolution to mixed oxides. Mater Res Bull 34: 1707-1717.

15. Xia SJ, Liu FX, Ni ZM, Shi W, Xue JL, et al. (2014) Ti-based layered double hydroxides: Efficient photo catalysts for azodyes degradation under visible light. Appl Catal B: Environ 144: 570-579.

16. De Roy A, Forano C, Besse JP (2001) Layered Double Hydroxides: Synthesis and Postsynthesis

Modificatiom in Layered Double Hydroxides: Present and Future, Nova Science, New York, USA.

17. Cunha VRR, De Souza RB, Da Fonseca Martins AMCRP, Koh IHJ, Constantino VRL (2016) Accessing the biocompatibility of layered double hydroxide by intramuscular implantation: Histological and microcirculation evaluation. Sci Rep 6: 1-10.

18. Duda F, Kieke M, Waltz F, Schweinefuß ME, Badar M, et al. (2015) Highly biocompatible behavior and slow degradation of a LDH (layered double hydroxide)-coating on implants in the middle ear of rabbits. J Mater Sci Mater Med 26: 1-8.

19. Perioli L, Mutascio P, Pagano C (2013) Influence of the nanocomposite MgAl-HTlc on gastric absorption of drugs: in vitro and ex vivo studies. Pharm Res 30: 156-166.

20. Djebbi MA, Bouaziz Z, Elabed A, Sadiki M, Elabed S, et al. (2016) Preparation and optimization of a drug delivery system based on berberine chloride-immobilized MgAl hydrotalcite. Int J Pharm 506: 438-448.

21. Nabipour H, Sadr MH (2015) Controlled release of Diclofenac, an antiinflammatory drug by nanocompositing with layered zinc hydroxide. J Porous Mater 5: 447-54.

22. Fontes DAF, de Lyra MAM, de Andrade JKF, de Medeiros Schver GCR, Rolim LA, et al. (2016) CaAl-layered double hydroxide as a drug delivery system: effects on solubility and toxicity of the antiretroviral efavirenz. J Incl Phenom Macrocycl Chem 85: 281-288.

23. Gao X, Chen L, Xie J, Yin Y, Chang T, et al. (2014) In vitro controlled release of vitamin $\mathrm{C}$ from $\mathrm{Ca} / \mathrm{Al}$ layered double hydroxide drug delivery system. Mater Sci Eng C 39: 56-60.

24. Djaballah R, Bentouami A, Benhamou A, Boury B, Elandaloussi EH, (2018) The use of Zn-Ti layered double hydroxide interlayer spacing property for low-loading drug and low-dose therapy. Synthesis, characterization and release kinetics study. J Alloys Compd 739: 559-567.

25. Kuznetsova A, Domingues PM, Silva T, Almeida A, Zheludkevich ML, et al. (2017) Antimicrobial activity of 2-mercaptobenzothiazole released from environmentally friendly nanostructured layered double hydroxides. J Appl Microbiol 122: 1207-1218.

26. Saifullah B, El Zowalaty ME, Arulselvan P, Fakurazi S, Webster TJ, et al. (2016) Synthesis, characterization, and efficacy of antituberculosis isoniazid zinc aluminum-layered double hydroxide based nanocomposites. Int J Nanomedicine 11: 3225-3237.

27. Li Y, Bi HY, Wang GW, Wang N, Chen CX, et al. (2016) Intercalation of Norfloxacin into Layered Double Hydroxides by Delamination/ Restacking Process and its Controlled-Release Property. J Dispers Sci Technol 37: 366-373.

28. Mei X, Xu S, Hu T, Peng L, Gao R, et al. (2017) Layered double hydroxide monolayers for controlled loading and targeted delivery of anticancer drugs. Nano Res 11(1): 1-11.
29. Xu T, Zhang J, Chi H, Cao F (2016) Multifunctional properties of organicinorganic hybrid nanocomposites based on chitosan derivatives and layered double hydroxides for ocular drug delivery. Acta Biomater 36: 152-163.

30. Cernei ER, Maxim A, Maxim DC, Mavru RB, Zegan G (2016) Textural Properties of Amoxicillin-Anionic Clays Composites for Possible Oral Diseases Uses. Rev Chim 67: 1306-1308.

31. Peng F, Wang D, Cao H, Liu X (2018) Loading 5-Fluorouracil into calcined $\mathrm{Mg} / \mathrm{Al}$ layered double hydroxide on AZ31 via memory effect. Mater Lett 213: 383-386

32. Ray S, Saha S, Sa B, Chakraborty J (2017) In vivo pharmacological evaluation and efficacy study of methotrexate-encapsulated polymercoated layered double hydroxide nanoparticles for possible application in the treatment of osteosarcoma. Drug Deliv Transl Res 7: 259-275.

33. Chen Y-X, Zhu R, Xu Z, Ke Q-F, Zhang C-Q, et al. (2017) Self-assembly of pifithrin- $\alpha$-loaded layered double hydroxide/chitosan nanohybrid composites as a drug delivery system for bone repair materials. J Mater Chem B 5: 2245-2253.

34. Senapati S, Thakur R, Verma SP, Duggal S, Mishra DP, et al. (2016) Layered double hydroxides as effective carrier for anticancer drugs and tailoring of release rate through interlayer anions. J Control Release 224: 186-198.

35. Carja G, Grosu E-F, Petrarean C, Nichita N (2015) Self-assemblies of plasmonic gold/layered double hydroxides with highly efficient antiviral effect against hepatitis B virus. Nano Res 11: 3512-3523.

36. Nakayama H, Hatakeyama A, Tsuhako M (2010) Encapsulation of nucleotides and DNA into Mg-Al layered double hydroxide. Int J Pharm 393: 104-111.

37. Balcomb B, Singh M, Singh S (2015) Synthesis and Characterization of Layered Double Hydroxides and Their Potential as Nonviral Gene Delivery Vehicles. Chemistry Open 4: 137-145.

38. Mohsin SMN, Hussein MZ, Sarijo SH, Fakurazi S, Arulselvan P, et al. (2014) Characterisation and Cytotoxicity Assessment of UV AbsorbersIntercalated Zinc/Aluminium-Layered Double Hydroxides on Dermal Fibroblast Cells. Sci Adv Mater 6: 648-658.

39. Cursino ACT, da Silva Lisboa F, dos Santos Pyrrho A, de Sousa VP, Wypych F (2013) Layered double hydroxides intercalated with anionic surfactants/benzophenone as potential materials for sunscreens. J Colloid Interface Sci 397: 88-95.

40. Li Y, Tang L, Ma X, Wang X, Zhou W, et al. (2017) Synthesis and characterization of Zn-Ti layered double hydroxide intercalated with cinnamic acid for cosmetic application. J Phys Chem Solids 107: 62-67.

41. Mohsin SMN, Hussein MZ, Sarijo SH, Fakurazi S, Arulselvan P, et al. (2014) Optimization of UV absorptivity of layered double hydroxide by intercalating organic UV-absorbent molecules. J Biomed Nanotechnol 10: $1490-1500$.

42. Soussou A, Gammoudi I, Morote F, Kalboussi A, Cohen-Bouhacina T, et al. (2017) Efficient immobilization of tyrosinase enzyme on layered double hydroxide hybrid nanomaterials for electrochemical detection of polyphenols. IEEE Sens J 17: 4340-4348.

43. Datta S, Christena LR, Rani Y, Rajaram S (2013) Enzyme immobilization: an overview on techniques and support material. 3 Biotech 3(1): 1-9.

44. Wang Y, Wang Z, Rui Y, Li M (2014) Horseradish peroxidase immobilization on carbon nanodots/CoFe layered double hydroxides: Direct electrochemistry and hydrogen peroxide sensing. Biosens Bioelectron 64: 57-62.

45. Baccar ZM, Hafaiedh I (2011) Immobilization of HRP Enzyme on Layered Double Hydroxides for Biosensor Application. Int J Electrochem 2011: $1-5$.

46. Chen X, Fu C, Wang Y, Yang W, Evans DG (2008) Direct electrochemistry and electrocatalysis based on a film of horseradish peroxidase 
intercalated into Ni-Al layered double hydroxide nanosheets. Biosens Bioelectron 24: 356-361.

47. Shan D, Cosnier S, Mousty C (2003) HRP wiring by redox active layered double hydroxides: Application to the mediated $\mathrm{H} 2 \mathrm{O} 2$ detection. Anal Lett 36: 909-922.

48. Geraud E, Prevot V, Forano C, Mousty C (2008) Spongy gel-like layered double hydroxide-alkaline phosphatase nanohybrid as a biosensing material. Chem Commun pp. 1554-1556.

49. Mousty C, Kaftan O, Prevot V, Forano C (2008) Alkaline phosphatase biosensors based on layered double hydroxides matrices: Role of LDH composition. Sensors Actuators, B Chem 133: 442-448.

50. Gong J, Guan Z, Song D (2013) Biosensor based on acetylcholinesterase immobilized onto layered double hydroxides for flow injection/ amperometric detection of organophosphate pesticides. Biosens Bioelectron 39: 320-323.

51. Zou N, Plank J (2015) Intercalation of cellulase enzyme into a hydrotalcite layer structure. J Phys Chem Solids 76: 34-39.

52. Zhan T, Wang X, Li X, Song Y, Hou W (2016) Hemoglobin immobilized in exfoliated Co2Al LDH-graphene nanocomposite film: Direct electrochemistry and electrocatalysis toward trichloroacetic acid. Sensors Actuators, B Chem 228: 101-108.

53. Zhan T, Wang X, Zhang Y,Song Y, Liu X, et al. (2015) Directelectrochemistry and electrocatalysis of hemoglobin immobilized in layered double hydroxides modified with amino functionalized ionic liquid through coprecipitation technique. Sensors Actuators B Chem 220: 1232-1240.
54. Scavetta E, Ballarin B, Berrettoni M, Carpani I, Giorgetti M, et al. (2006) electrochemical sensors based on electrodes modified with synthetic hydrotalcites. Electrochim Acta 51: 2129-2134.

55.Zhan T, Song Y, Tan Z, Hou W (2017) Electrochemical bisphenol A sensor based on exfoliated Ni2Al-layered double hydroxide nanosheets modified electrode. Sensors Actuators B Chem 238: 962-971.

56. Wang L, Wang Y, Wang X (2017) Supporting information Synthesis and in Vitro characterization of Fe $3+$-doped layered double hydroxide nanorings as a potential imageable drug delivery system 10: 1140 .

57. Samuei S, Fakkar J, Rezvani Z, Shomali A, Habibi B (2017) Synthesis and characterization of graphene quantum dots/CoNiAl-layered double-hydroxide nanocomposite: Application as a glucose sensor. Anal Biochem 521: 31-39.

58. Wang X, Zheng Y, Yuan J, Shen J, Hu J, et al. (2017) Three-dimensional NiCo Layered Double Hydroxide Nanosheets Array on Carbon Cloth, Facile Preparation and Its Application in Highly Sensitive Enzymeless Glucose Detection. Electrochim Acta 224: 628-635.

59. Fu S, Fan G, Yang L, Li F (2015) Non-enzymatic glucose sensor based on Au nanoparticles decorated ternary Ni-Al layered double hydroxide/ single-walled carbon nanotubes/graphene nanocomposite. Electrochim Acta 152: 146-154.

60. Zhu Z, Qu L, Guo Y, Zeng Y, Sun W, et al. (2010) electrochemical detection of dopamine on a $\mathrm{Ni} / \mathrm{Al}$ layered double hydroxide modified carbon ionic liquid electrode. Sensors Actuators B Chem 151: 146-152.
CC (i) This work is licensed under Creative

Submission Link: http://biomedres.us/submit-manuscript.php

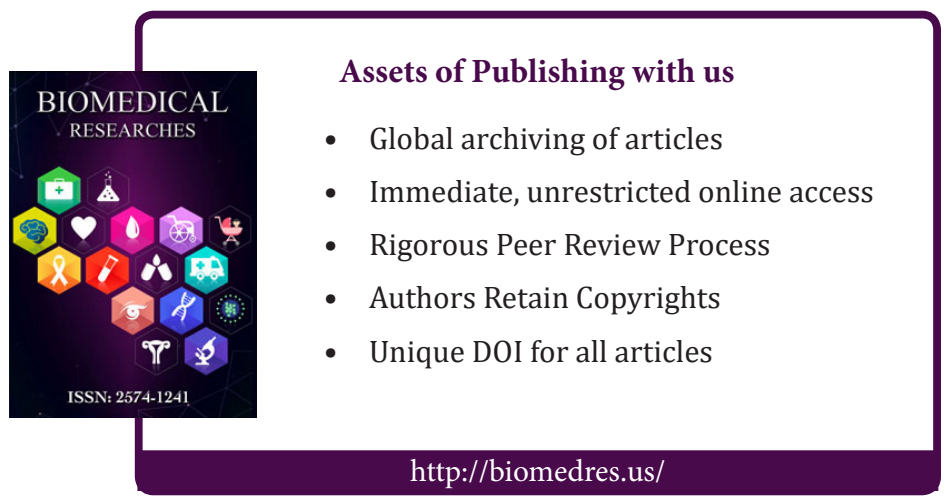

